\title{
Characterization of subsurface fluxes at the plot scale during flash floods in the Valescure catchment, France
}

\author{
Christophe BOUVIER ${ }^{1}$, Marko Adamovic ${ }^{1}$, Pierre-Alain Ayral ${ }^{2}$, Pascal Brunet ${ }^{1}$, \\ Jean-Francois Didon-Lescot ${ }^{3}$, Jean-Marc Domergue ${ }^{3}$, and Rosario Spinelli ${ }^{2}$ \\ ${ }^{1}$ HydroSciences Montpellier \\ ${ }^{2}$ Ecole des Mines dÁles \\ ${ }^{3} \mathrm{UMR}-7300$ ESPACE CNRS
}

November 6, 2020

\begin{abstract}
This study focuses on a 10-m2 plot within a granitic hillslope in Cevennes mountainous area in France, in order to study infiltration and subsurface hydrological processes during heavy rainfalls and flash floods. The monitoring device included water content at several depths $(0-70 \mathrm{~cm}$ for the shallow soil water; $0-10 \mathrm{~m}$ for the deep water) during both intense artificial and natural rainfall events, chemical and physical tracers, time-lapse electrical resistivity tomography. During the most intense events, the infiltrated water was estimated to be some hundreds of millimeters, which largely exceeds the topsoil capacity ([?]40 cm deep in most of the cases). The weathered/fractured rock area below the soil clearly has an active role in the water storage and sub-surface flow dynamics. Vertical flow was dominant in the first 0-10m, and lateral flow was effective at 8-10 $\mathrm{m}$ depth, at the top of the saturated area. The speed of the vertical flow was estimated between 1 and $10 \mathrm{~m} / \mathrm{h}$, whereas it was estimated between 0.1 and $1 \mathrm{~m} / \mathrm{h}$ for the lateral flow. The interpretation of the experiments led to a local pattern of the 2D-hydrological processes and profile properties. It suggests that fast triggering of floods at the catchment scale cannot be explained by a mass transfer within the hillslope, but should be due to a pressure wave propagation through the bedrock fractures, which allows exfiltration of the water downstream the hillslope.
\end{abstract}

\section{Hosted file}

Article_Parcelle_submitted.pdf available at https://authorea.com/users/373553/articles/ 491222-characterization-of-subsurface-fluxes-at-the-plot-scale-during-flash-floods-inthe-valescure-catchment-france 


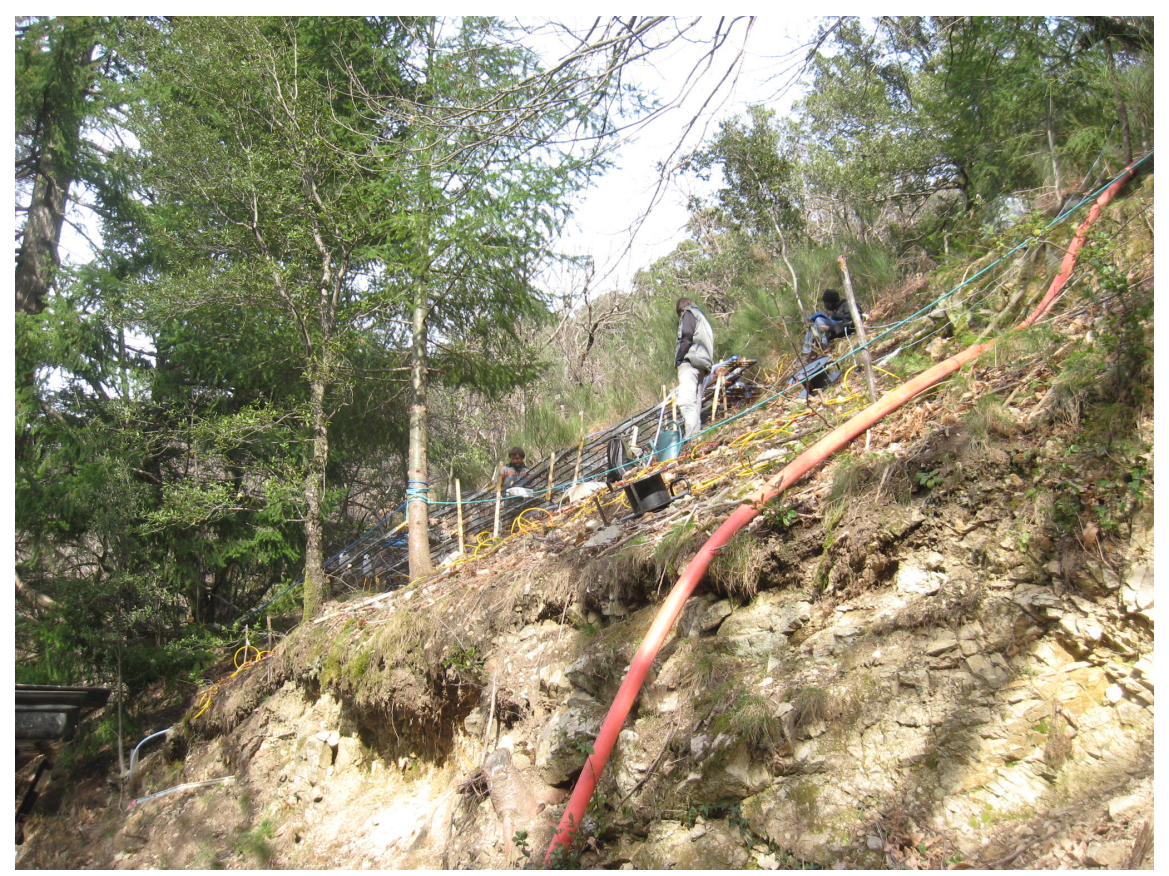




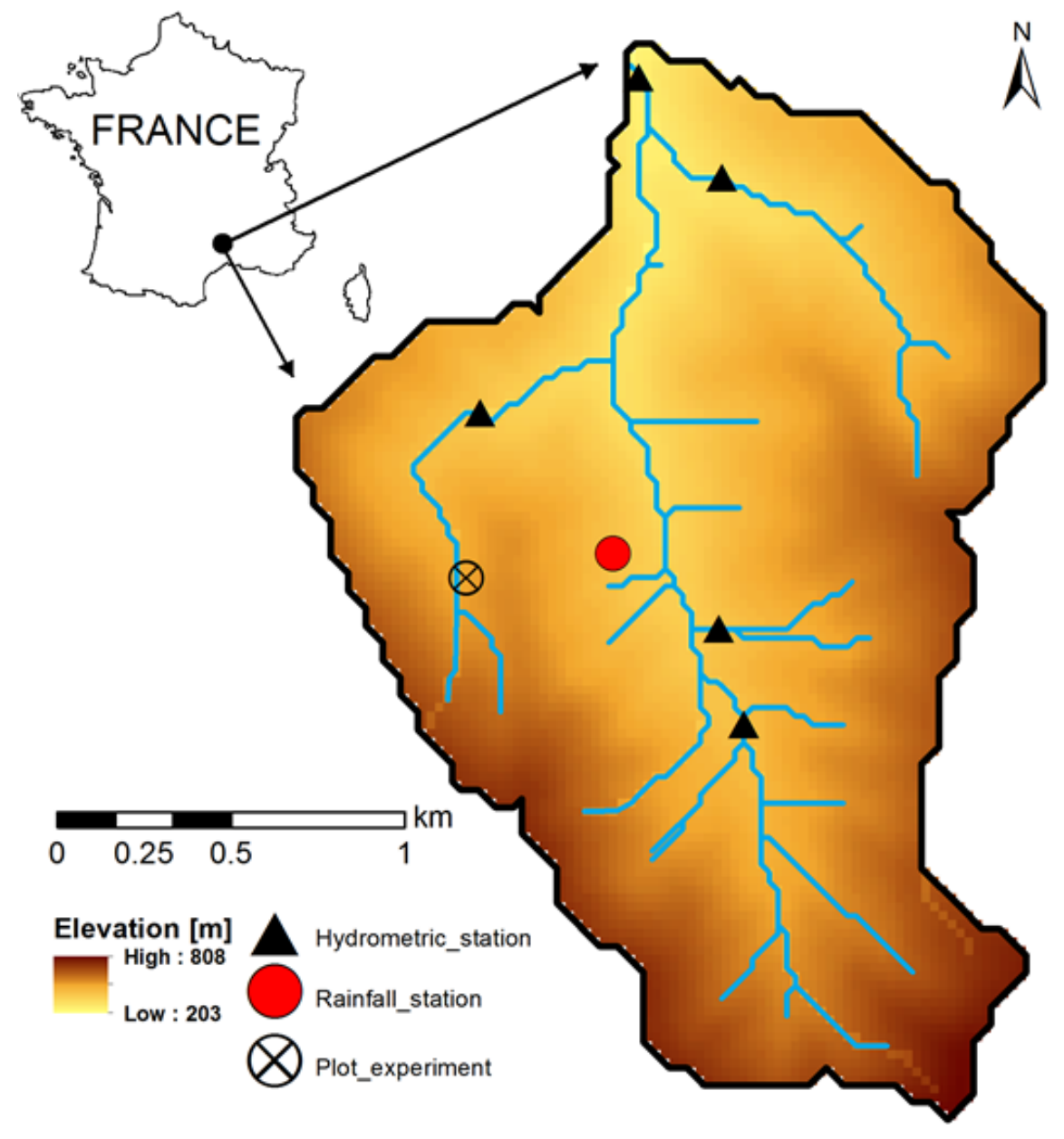




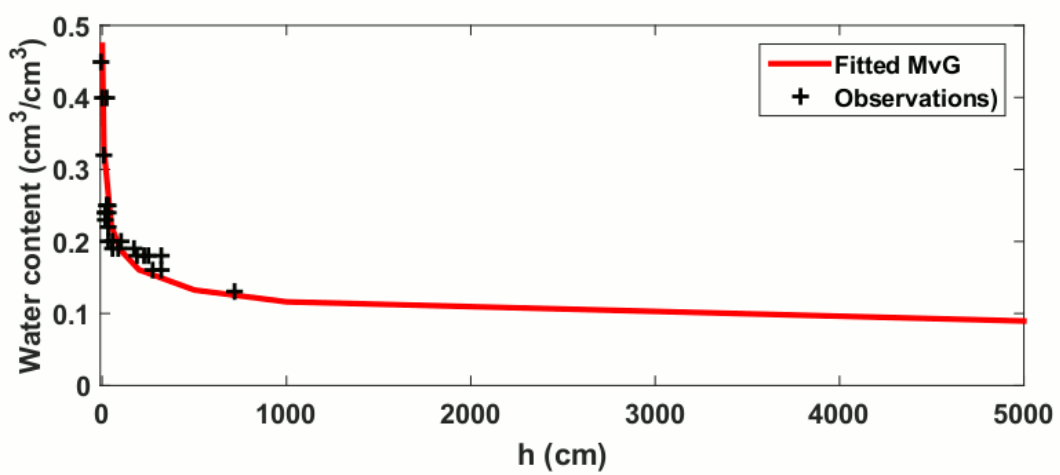




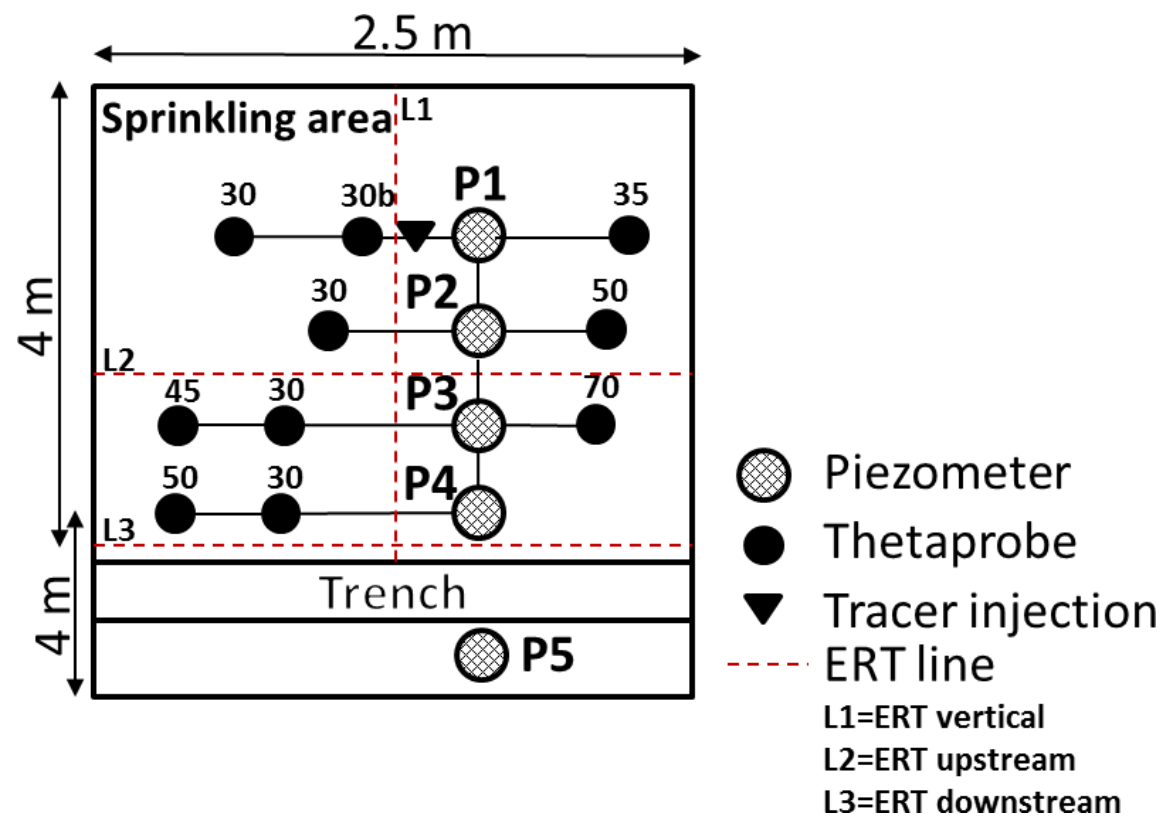

9h20 TU Initial state before the artificial rainfall

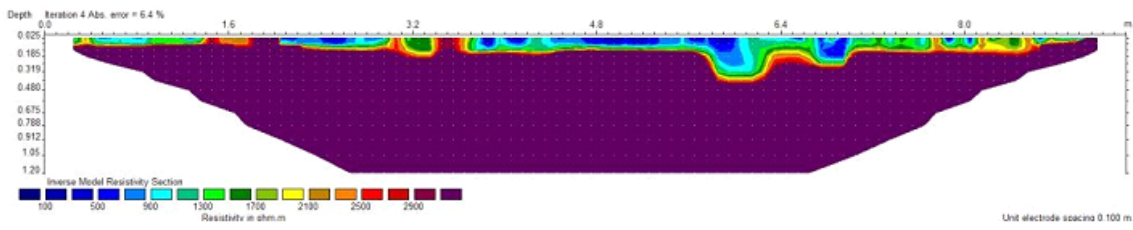

$10 \mathrm{~h} 30 \mathrm{TU} 70 \mathrm{mn}$ after the beginning of the artificial rainfall

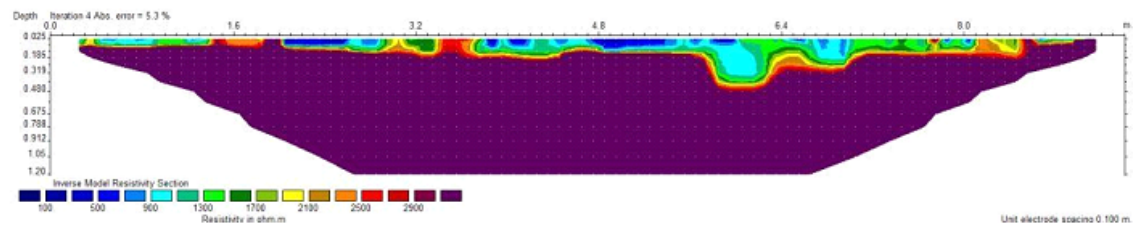

$10 \mathrm{~h} 43 \mathrm{TU}$ just after the salt injection

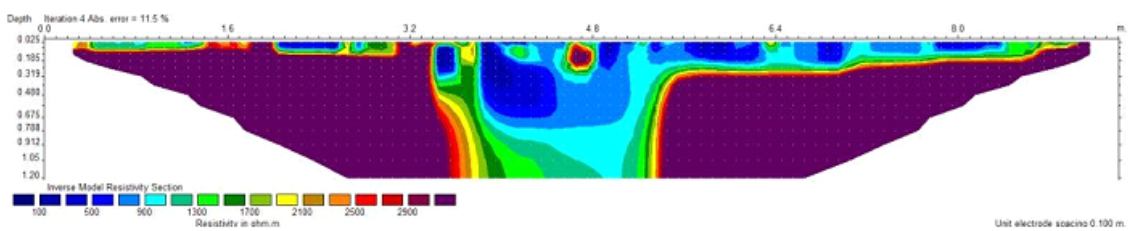



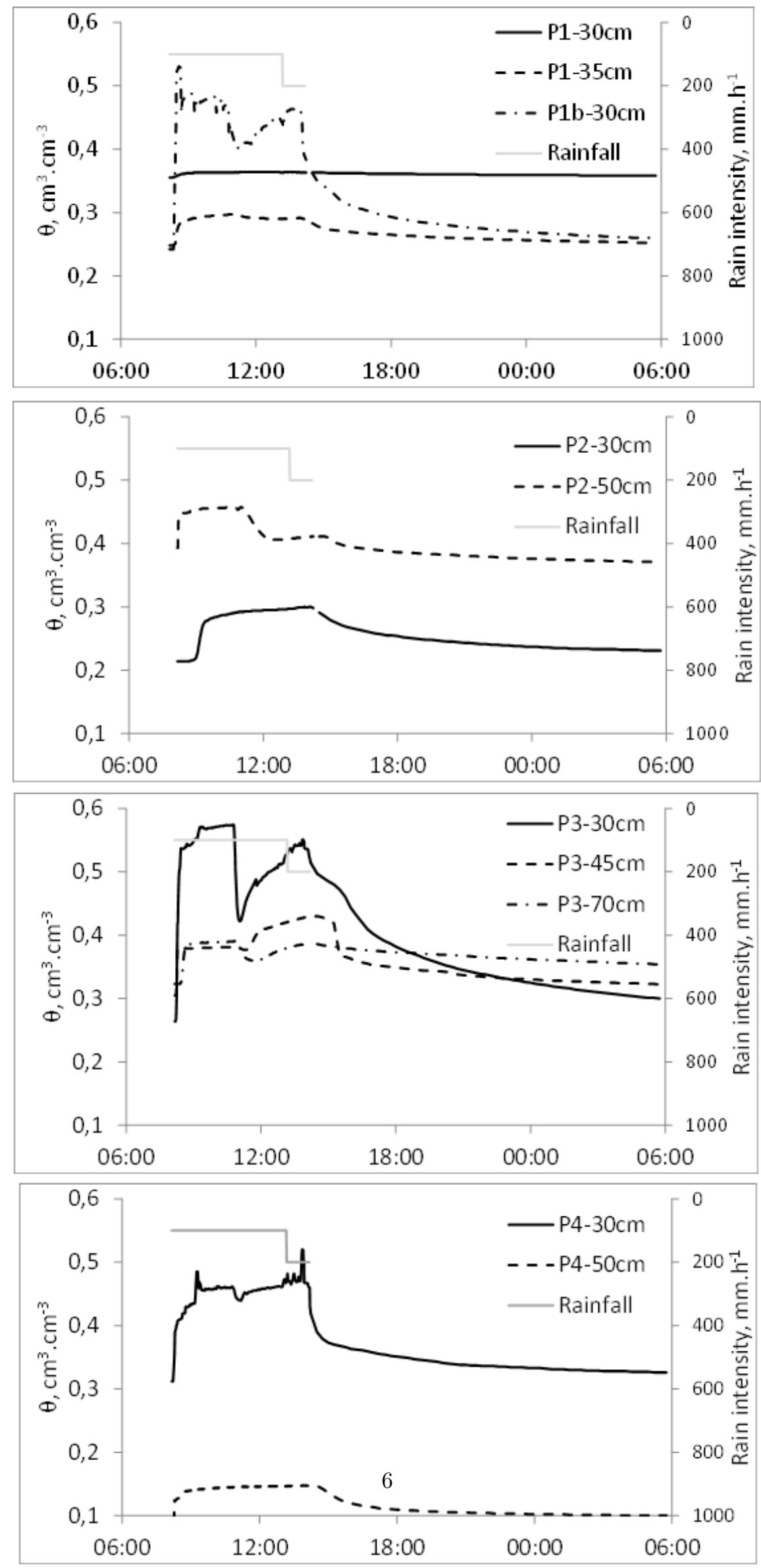

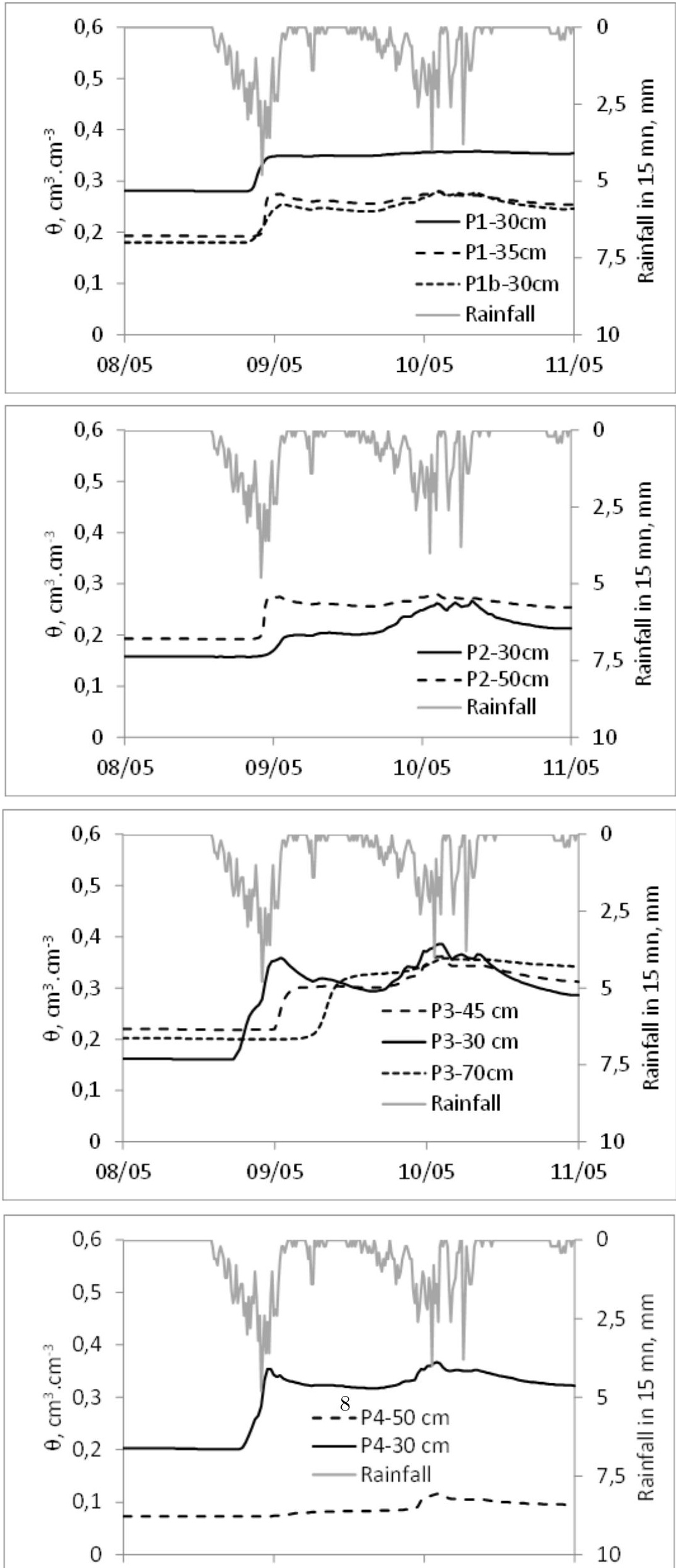

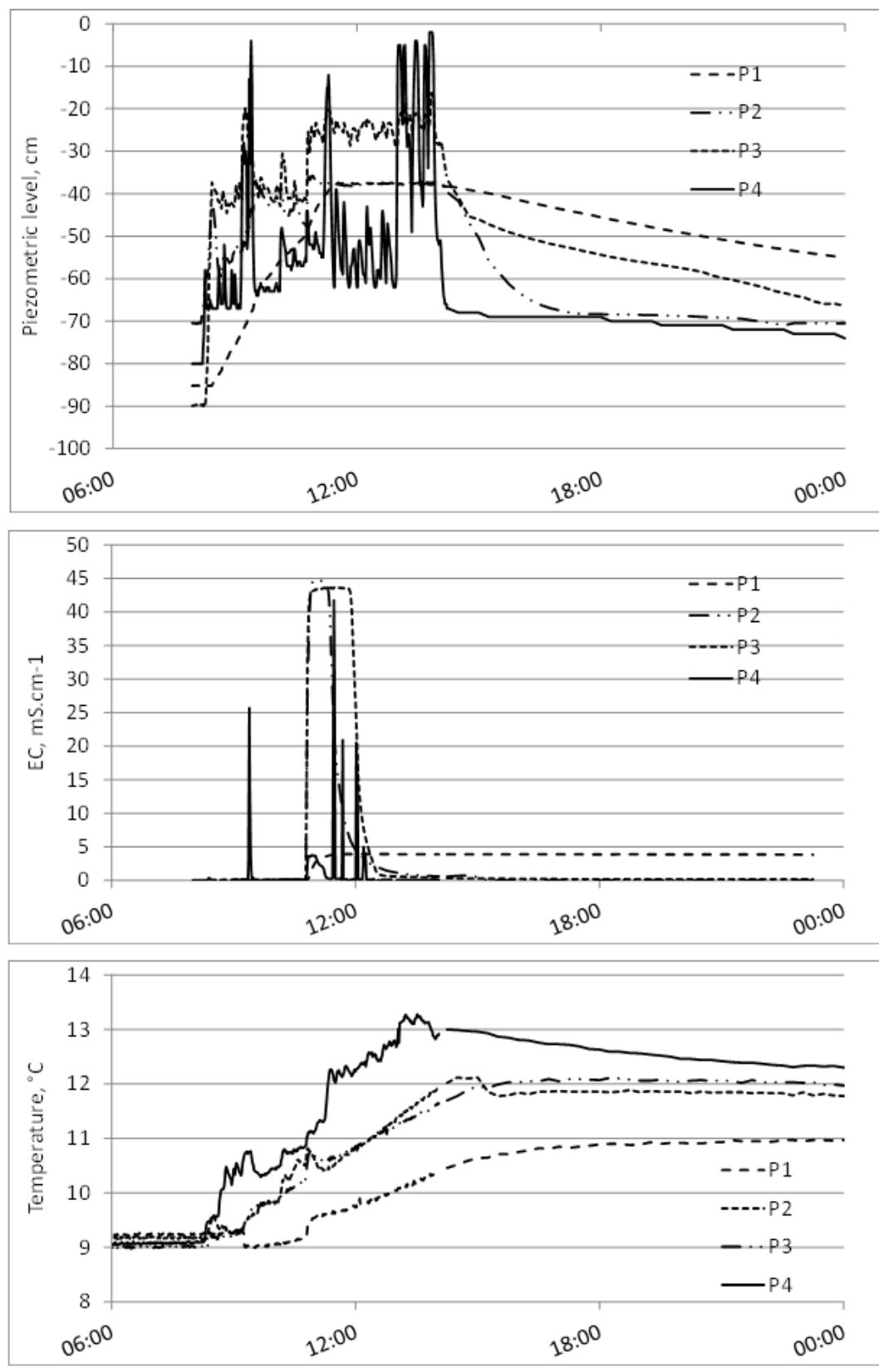

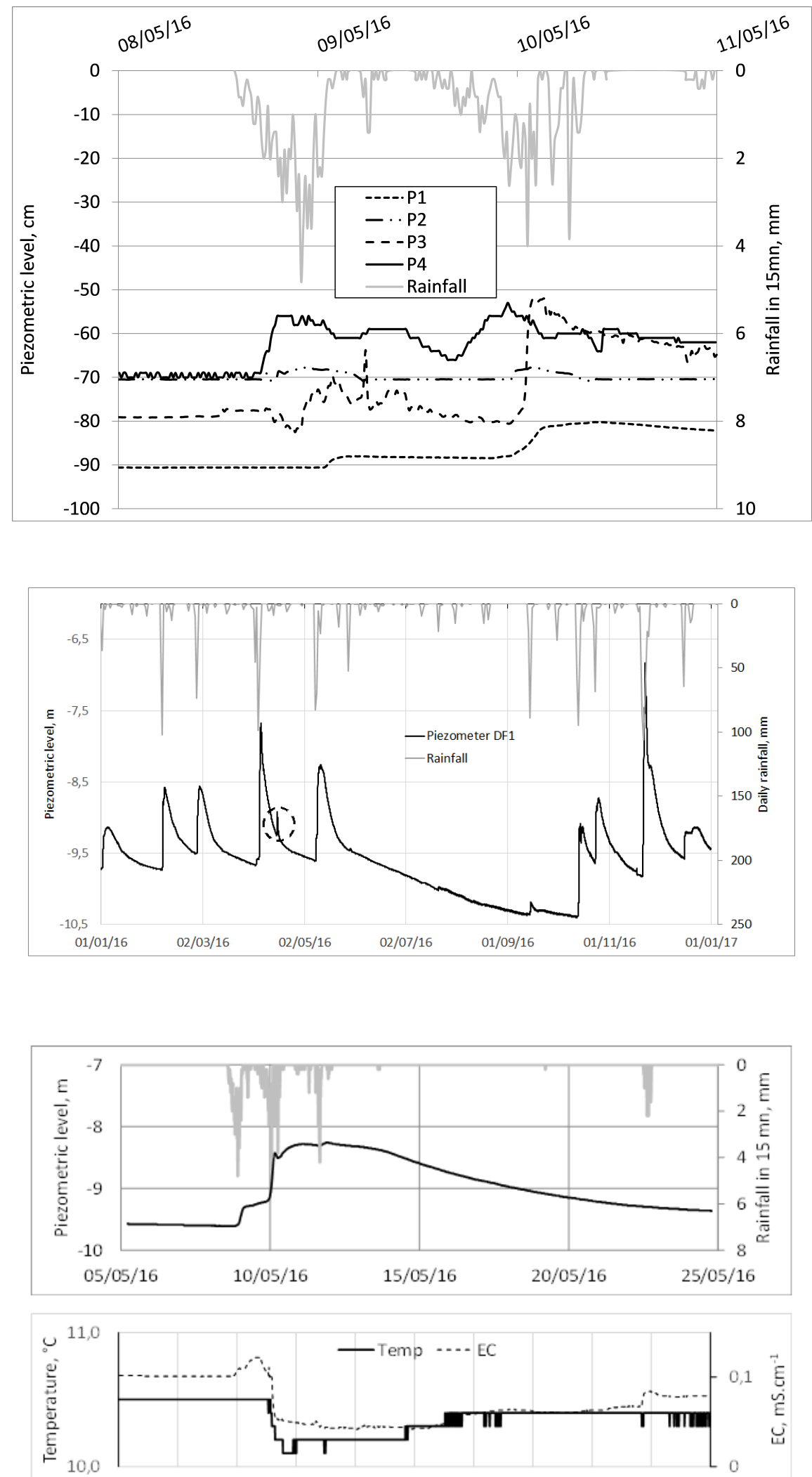

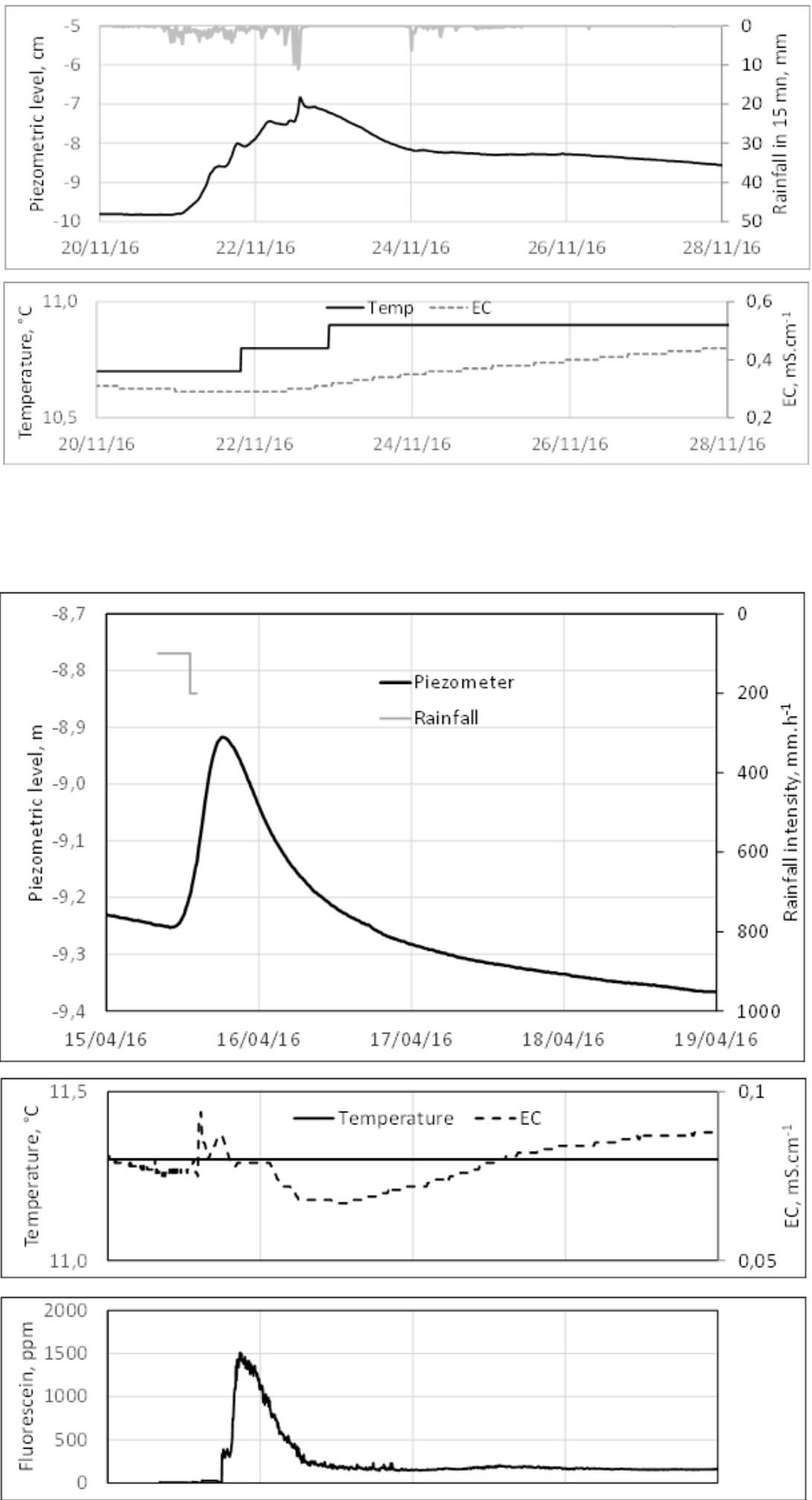


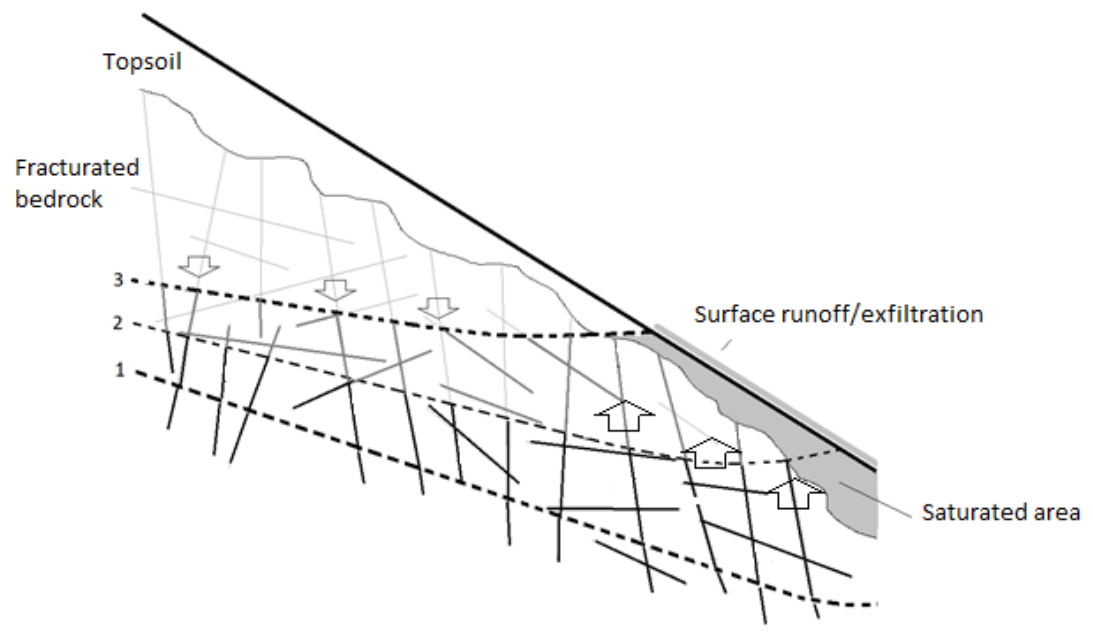

